\title{
MENSURAÇÃO DA LUCRATIVIDADE DOS CLIENTES EM UMA EMPRESA PRESTADORA DE SERVIÇOS CONTÁBEIS
}

Flávio Roberto Mantovani

Professor Doutor Coordenador do curso de Ciências Contábeis da Universidade Presbiteriana Mackenzie (UPM).

E-mail:flavio.mantovani@mackenzie.br

\section{Gregory Gonçalves Pereira Silva}

Graduado em Ciências Contábeis pela Universidade Presbiteriana Mackenzie (UPM).

E-mail: gregorysilva169@hotmail.com

\section{Leonardo Fiorelli Carmassi}

Graduado em Ciências Contábeis pela Universidade Presbiteriana Mackenzie (UPM). 


\section{RESUMO}

A modelagem de mensuração da lucratividade dos clientes é uma ferramenta importante para a gestão econômica da empresa, contudo, muitos administradores ainda não se utilizam desse artefato gerencial, provavelmente por falta de recursos e conhecimento ou até mesmo por considerarem desnecessário o seu uso. Nesse contexto, o presente estudo objetivou, por meio de uma abordagem intervencionista, implementar na empresa um mecanismo de controle de custos passível de mensurar a rentabilidade que cada cliente representa para a empresa, apresentando aos gestores um resultado mais transparente sobre sua lucratividade e a importância desse artefato gerencial. Uma empresa, que não utilizava o método mencionado, foi selecionada, e, a partir da sua implementação, buscou-se demonstrar os benefícios que esse mecanismo pode trazer para a gestão. A intervenção mostrou para os gestores uma visão clara de quais são os clientes rentáveis e não rentáveis para a empresa, além de indicar possíveis processos de melhoria.

\section{PALAVRAS-CHAVE}

Lucratividade do cliente. Custeio baseado em atividades. Serviços contábeis.

\section{INTRODUÇÃO}

Para uma empresa prestadora de serviços contábeis, a rentabilidade do cliente representa um grande desafio para os seus administradores. Nesse sentido, a informação contábil financeira e gerencial é a principal ferramenta de gestão para o empresário que busca o crescimento de sua empresa. Quando utilizada como uma ferramenta de gestão, pode trazer uma vantagem competitiva para a empresa, pois a melhor compreensão dos custos, das despesas e do capital investido pode proporcionar a decisão mais assertiva nos negócios (SERVIÇO BRASILEIRO DE APOIO ÀS MICRO E PEQUENAS EMPRESAS, 2012).

De acordo com Kaplan e Norton (2000), a empresa deverá identificar seus principais clientes a fim de diversificar setores e estabelecer os objetivos e os indicadores de lucratividade de cada um. Esse fator será de suma importância para a empresa determinar a sua estratégia em relação aos clientes, de maneira a combinar preços e serviços. Essa proposta de valor mostra o que a empresa poderá fazer pelo seu cliente, de maneira eficaz ou diferente de seu concorrente. 
Conforme asseveram Guerreiro et al. (2008b), o conhecimento dos custos de atendimento ou custos para servir é de suma importância para os gestores da empresa poderem descobrir a verdadeira rentabilidade das diferentes atividades que são feitas diariamente no atendimento das necessidades dos clientes.

Para Gupta e Lehmann (2006), os clientes integram os ativos da organização e representam a razão da sua existência. Sem clientes a empresa não vai prosperar, pois não conseguirá gerar receitas e consequentemente nenhum resultado.

A influência que os clientes exercem direta ou indiretamente no desempenho das empresas pode provocar interesse nos administradores que desejam compreender os efeitos práticos da aplicação de suas estratégias no negócio (MANTOVANI, 2012).

Considera-se relevante a abordagem intervencionista do estudo, pois a metodologia desenvolvida para controlar os custos e mensurar a lucratividade do cliente possibilitará aos administradores da empresa de serviços contábeis a gestão do desempenho da empresa a partir da perspectiva do cliente.

Com base em uma abordagem intervencionista, este trabalho tem como pro- pósito geral a implementação de um mecanismo de controle de custos que permita aos gestores da Contasp condições de mensurar a lucratividade dos seus clientes. A partir do objetivo geral, delineiam-se os seguintes objetivos específicos: 1. implantar o método de custeio $\mathrm{ABC}$ nos negócios da empresa; 2. atribuir custos e despesas para cada cliente; 3 . calcular a lucratividade de cada cliente individualmente.

Para preservar a identidade da empresa, adotou-se o nome fictício de Contábil. A empresa pode ser caracterizada como de pequeno porte, possui três funcionários e uma pequena carteira de clientes. É tributada pelo Simples Nacional, opera no segmento contábil e está localizada na região metropolitana do município de São Paulo.

A empresa foi fundada em 2015, constituída por uma sociedade de cinco contabilistas experientes no ramo. Iniciaram suas atividades com o objetivo de desenvolver uma empresa moderna e competitiva, com especialidades em diversas áreas, como auditoria, custos, valuation, gestão financeira, gestão de tributos, treinamento em gestão contábil e financeira em geral e com o que há de mais moderno no planejamento, na gestão e governança de empresas. 
O foco da empresa é fornecer serviços de assessoria empresarial e contábil, financeira e administrativa. O objetivo dos associados é buscar sempre a satisfação dos seus clientes de maneira a agregar valor ao relacionamento com estes.
Em seu plano estratégico, a Contábil possui sua missão, sua visão e seus valores, como mostra o Quadro 1.

\begin{tabular}{|c|c|}
\hline Missão & Visão \\
\hline $\begin{array}{l}\text { Ser uma empresa provedora de serviços de } \\
\text { consultoria contábil e financeira reconhecida pelos } \\
\text { nossos parceiros pela excelência dos serviços, } \\
\text { através da aplicação do conhecimento em soluções } \\
\text { inovadoras e exitosas. }\end{array}$ & $\begin{array}{l}\text { Agregar valor aos nossos parceiros pela contribuição } \\
\text { no atingimento dos seus objetivos estratégicos, } \\
\text { proporcionando informações que possibilitem } \\
\text { tomadas de decisão mais assertivas. }\end{array}$ \\
\hline Valores & Atendimento \\
\hline $\begin{array}{l}\text { Excelência: Entregamos o que prometemos, de } \\
\text { forma eficiente e precisa. Agregamos valor para } \\
\text { exceder as expectativas. }\end{array}$ & $\begin{array}{l}\text { Nossa proposta é de um atendimento diferenciado } \\
\text { ao cliente. Queremos ser parceiros no negócio. Ao } \\
\text { fazer os registros contábeis, queremos entender o } \\
\text { seu negócio e produzir relatórios que possam ser } \\
\text { utilizados no dia a dia na gestão da empresa. }\end{array}$ \\
\hline
\end{tabular}

QUADRO 1 - Plano estratégico da Contábil Fonte: Site da empresa (2018).

\section{REFERENCIAL TEÓRICO}

\section{Rentabilidade e mensuração}

De acordo com Iudícibus (1988), entender o real desempenho de uma entidade em certo período exige que o lucro seja relacionado a algum fator determinante que demonstre o quão grande é a empresa. Existem diversos indicadores que demons- tram essa "grandiosidade" da empresa, como a quantidade de vendas e serviços e seus números na contabilidade fornecidos no seu balanço patrimonial, nos números dos ativos, nos ativos operacionais e em seu patrimônio líquido. Assim, é calculada a rentabilidade quando se deseja ter uma ideia da lucratividade das operações, de onde se originam e onde se aplicam os recursos utilizados pelas entidades. 
Segundo Hastenteufel e Larentis (2015, p. 61):

A análise da rentabilidade de clientes, que nada mais é do que a apuração dos custos para atender determinado cliente obtendo assim a parcela de margem de contribuição para o lucro total da empresa, tem sido considerada de grande importância para o processo de formulação de estratégias e a otimização dos lucros da empresa, pois, através desta análise, indica-se a lucratividade individual de cada cliente.

O cálculo da rentabilidade do cliente leva em conta os custos para servir o cliente, considerando o tempo de trabalho e outras despesas em geral. Nesse contexto de rentabilidade, dois temas se destacam: os custos de mão de obra e hora disponíveis para determinado cliente e os custos das atividades administrativas relacionados ao atendimento ao cliente e que são mensurados por meio da metodologia do custeio baseado em atividades (activity based costing - ABC) (GUERREIRO et al., 2008b).

Assaf Neto (2009) considera que a rentabilidade pode ser uma avaliação econômica do desempenho da empresa, di- mensionando o retorno sobre os investimentos realizados e a lucratividade apresentada pelas vendas.

Thomé (2001) recomenda que a entidade prestadora de serviços contábeis use um mecanismo de controle de custos, um gráfico dos desembolsos da empresa, uma planilha de custos. Por meio de gráficos e planilhas, a empresa obterá informações de quanto realmente vale o serviço que ela está prestando e se os honorários a serem cobrados não estão prejudicando o cliente. Assim, é possível verificar a rentabilidade dos serviços prestados.

Na visão de Guerreiro et al. (2008c), as empresas geralmente analisam a rentabilidade de seus produtos e serviços pelo conceito de Mark-up que é uma diferença entre o custo de um bem ou serviço e seu preço de venda.

Segundo Ross, Jordan e Westerfield (2008, p. 64), “a rentabilidade é uma medida de eficiência que está relacionada com o retorno por unidade monetária investida”. Portanto, é correto dizer que a rentabilidade é uma certa proporção entre a quantidade investida pelos empreendedores e a quantidade ganha com o investimento. A rentabilidade é uma informação sobre o desempenho econômico. 
Nesse sentido, destaca-se a análise de rentabilidade dos clientes que é a principal ferramenta para aperfeiçoar os lucros da empresa, podendo vir a ser útil na criação de estratégias. Essa análise tem como principal foco a lucratividade e os custos de atendimento dos clientes (GUERREIRO et al., 2008a).

\section{Custos}

A contabilidade de custos é um sistema gerador de informações para os diversos níveis gerenciais, organizando e registrando os dados operacionais das atividades da empresa em diferentes modos. Essa é a área que trata dos gastos diretos e indiretos para a produção de bens ou serviços. Saber administrar os custos que incorreram e que irão incorrer é determinante para a gestão tomadora de decisão, pois influenciará na maioria das vezes diretamente na formação do preço de venda (MARTINS, 2003).

Segundo Ribeiro (1997, p. 27), o significado de custos dentro da contabilidade pode ser muito amplo:

Em uma empresa comercial pode ser utilizada para representar o custo das compras de mercadorias, o custo das merca- dorias disponíveis para venda, o custo das mercadorias vendidas etc. Em uma empresa de prestação de serviços, pode ser utilizada para representar o custo dos materiais adquiridos para aplicação na prestação de serviços, o custo dos serviços prestados etc. Em uma empresa industrial, pode ser utilizada para representar o custo das compras de matérias-primas, o custo das matérias-primas disponíveis, o custo das matérias-primas aplicadas no processo de fabricação, o custo direto de fabricação, o custo indireto de fabricação, o custo da produção acabada no período, o custo dos produtos vendidos etc.

Martins (2003) cita duas principais funções presentes na contabilidade de custos: o auxílio ao controle (fornecendo dados e orçamentos e contribuindo para uma análise comparativa dos valores anteriormente incorridos) e a ajuda às tomadas de decisão (observação de valores relevantes para a análise dos processos que trazem consequências de curto e longo prazos). Iudícibus (1998) define custo como um ato de sacrifício, ou seja, quanto foi gasto (sacrifício financeiro) para adquirir determinado bem ou serviço. 
Os custos podem ser classificados basicamente em diretos e indiretos. Os custos diretos são objetivos e apropriáveis ao produto acabado, ou seja, estão ligados diretamente a cada tipo de bem, como matéria-prima e mão de obra direta. Os custos indiretos não são os identificados diretamente em produtos e serviços, mas aqueles incorridos dentro do processo de produção, que possuem uma aproximação atribuída aos produtos por algum critério de rateio, como segurança, peças de manutenção e mão de obra indireta (IUDÍCIBUS, 1998).

De acordo com Vanderbeck e Nagy (2001, p. 5):

A importância das informações contábeis para a operação bem-sucedida de uma empresa, incluindo dados sobre custos específicos, foi reconhecida há muito tempo. Entretanto, no atual ambiente da economia globalizada, essas informações são mais críticas do que nunca.

Vanderbeck e Nagy (2001) afirmam que a contabilidade de custos entrega para a gestão da empresa dados detalhados sobre o que foi desembolsado nas operações e da- dos que permitirão o planejamento futuro da entidade. Assim, a contabilidade permite que a empresa aloque custos para as áreas mais rentáveis da operação da empresa.

\section{Custos para servir}

O custo para servir tem a intenção de analisar a rentabilidade de cada cliente, e, nesse contexto, a entidade terá informações para a formação de preços dos serviços e a lucratividade de cada um. Por meio desse recurso, é possível avaliar se um cliente é rentável ou não (ROBLES JR.; ROBLES; FARIA, 2005).

Segundo Guerreiro et al. (2008b, p. 7):

\begin{abstract}
Considera-se, como custo para servir, o custo das atividades administrativas, comerciais e logísticas - relacionadas com a prestação de serviços aos clientes, mensurado por meio da metodologia de custeio baseado em atividades, com o objetivo de propiciar a análise de lucratividade de clientes.
\end{abstract}

Para Kaplan e Narayanan (2001), nas entidades prestadoras de serviços, identificar a lucratividade de cada cliente é mais relevante do que a lucratividade de cada 
produto, porque, para atender um cliente, a empresa tem custos variados sobre cada um, dependendo do porte dele.

\begin{tabular}{ll}
\hline Clientes de alto custo & $\begin{array}{l}\text { Clientes de baixo } \\
\text { custo }\end{array}$ \\
\hline $\begin{array}{l}\text { Fazem pedidos de } \\
\text { serviços customizados. }\end{array}$ & $\begin{array}{l}\text { Fazem pedidos de } \\
\text { serviços padronizados. }\end{array}$ \\
\hline $\begin{array}{l}\text { Pedem quantidades } \\
\text { menores. }\end{array}$ & $\begin{array}{l}\text { Pedem quantidades } \\
\text { maiores. }\end{array}$ \\
\hline $\begin{array}{l}\text { Não há previsibilidade } \\
\text { de pedidos. }\end{array}$ & $\begin{array}{l}\text { Chegada dos pedidos é } \\
\text { previsível. }\end{array}$ \\
\hline Entrega personalizada. & Entrega padronizada. \\
\hline Mudança das & Não mudam as \\
necessidades de entrega. & condições das entregas. \\
\hline Atendimento diário. & Atendimento mensal. \\
\hline
\end{tabular}

QUADRO 2 - Clientes de alto e baixo custos Fonte: Adaptado de Kaplan e Cooper (1998).

Segundo Guerreiro (2008b), o custo para servir pode ser considerado uma maneira ou um sistema de melhoria da rentabilidade de cada cliente. Esse método dependerá do serviço que a empresa presta aos clientes, porque pode variar com o que a entidade desembolsa para atendê-los.

\section{Métodos de custeio}

Segundo Moura (2005), métodos de custeio são formas de como cada empresa irá alocar seus custos em sua produção ou prestação de serviço. Cada um dos métodos apresenta vantagens e desvantagens. Tais métodos são utilizados para reduzir custos, aumentar ou diminuir investimentos, ter conhecimento no valor dos objetos e evitar desperdícios. Existem três principais métodos de custeio: por absorção, variável e baseado em atividades.

De acordo com Brimson (1996, p. 27):

A abordagem da contabilidade por atividades para gerenciamento de custos divide uma empresa em atividades. Uma atividade descreve o que uma empresa faz - a forma como o tempo é gasto e os produtos do processo. A principal função de uma atividade é converter recursos (material, mão-de-obra e tecnologia) em produtos e serviços. A contabilidade por atividades identifica as atividades desenvolvidas em uma empresa e determina seu custo e desempenho tempo e qualidade.

\section{Custeio baseado em atividades}

O método $\mathrm{ABC}$ é "uma metodologia desenvolvida para facilitar a análise estratégica de custos relacionados com as atividades 
que mais impactam o consumo de recursos de uma empresa" (NAKAGAWA, 1994, p. 40). Dessa forma, o ABC tem como objetivo examinar a redução dos custos por meio de cortes com desperdícios, com a diminuição de operações que contribuem para a geração de custo que não agregam valor, ou seja, elementos que causam o consumo de atividades desnecessárias.

Segundo Kaplan e Cooper (1998, p. 94), $\mathrm{o} A B C$ pode ser definido como

Um mapa econômico das despesas e da lucratividade da organização baseado nas atividades organizacionais. Um sistema de custeio baseado em atividades oferece às empresas um mapa econômico de suas operações, revelando o custo existente e projetado de atividades e processos de negócios que, em contrapartida, esclarece o custo e a lucratividade de cada produto, serviço, cliente e unidade operacional.

Dessa forma, destaca-se o custeio por atividade, que se torna um princípio para o método de custeio ABC. Nakagawa (1994, p. 42) define a atividade "como um processo que combina, de forma adequada, pessoas, tecnologias, materiais, métodos e seu ambiente, tendo como objetivo a produção de produtos".

Conforme Padoveze (2015), os principais objetivos do método $A B C$, além de transferir o custo das atividades para os produtos e serviços, é ver o impacto que cada atividade causa na empresa e em sua estrutura, e, dessa maneira, comparar os custos dessas atividades ao longo do tempo, também em relação a concorrentes de outras empresas.

$\mathrm{O}$ diferencial do método $\mathrm{ABC}$ em relação aos outros métodos tradicionais é a forma de alocação dos custos indiretos aos produtos. Segundo Ferreira (2007), os custos indiretos não são mensuráveis de maneira clara e objetiva, sendo necessário direcioná-los utilizando o critério de rateio. Podem-se mencionar como exemplo serviços, produtos, clientes, linhas de produtos, canais de distribuição ou outro segmento de interesse da gerência.

De acordo com Padoveze (2015, p. 262):

As vantagens do custeamento por atividades, como método para proceder a uma distribuição mais acurada dos custos indiretos de fabricação aos produtos parecem claras. O método permite apurar custos de forma mais precisa, ao 
mesmo tempo que auxilia no processo de controle dos custos das atividades.

A operação desse método de custeio inicialmente estabelece uma relação entre os produtos e as atividades da empresa com os direcionadores de custos que são separados em primeiro e segundo estágios. Apuram-se os custos desses produtos ou atividades com a alocação desses custos via direcionadores. A Figura 1 apresenta a metodologia do sistema ABC (DURAN; RADAELLI, 2000).

Martins (2003) define "direcionador de custos" como o fator que determina a ocorrência de uma atividade. Uma vez que as atividades necessitam de recursos para serem realizadas, entende-se que a causa dos custos é gerada pelo direcionador, ou seja, o direcionador de custos determina a maneira como os recursos utilizam as atividades.

Na definição de Padoveze (2015), os direcionadores de custos são determinados por tarefas principais praticadas dentro da empresa, pois, quanto maior for a necessidade de esforço para consumir recursos e tempo, maior será o custo. Assim, surgiram os direcionadores de custos no método ABC.
Conforme Corrêa (2002, p. 14), “partindo do pressuposto que os recursos são consumidos pelas atividades desenvolvidas e que os produtos consomem essas atividades, a metodologia do $\mathrm{ABC}$ passou a ser utilizada para melhorar as informações de custos dos produtos”.

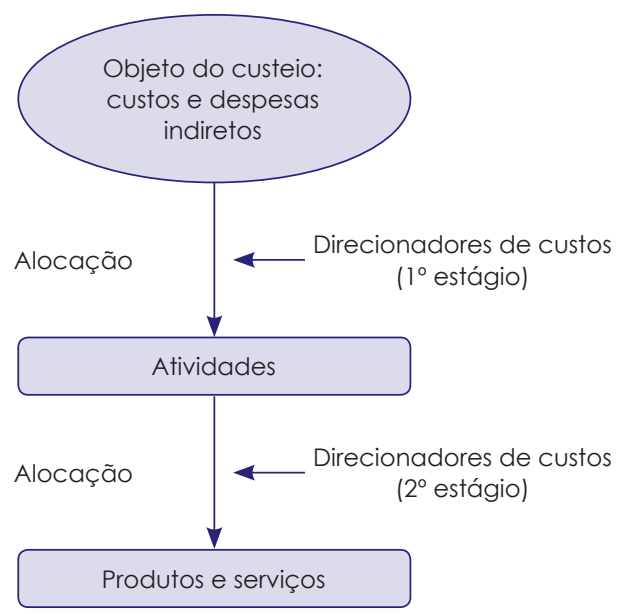

Figura 1 - Critério ABC, uma visão global Fonte: Leone (1997).

Martins (2003, p. 103) classifica os direcionadores como: "direcionadores de recursos" e "direcionadores de atividades". O direcionador de custos de atividade identifica a relação entre as atividades e os produtos, como o número de testes feitos numa linha de produção que revela o quanto determinada atividade realmente consumiu. Já o direcionador de custos de 
recursos identifica a relação entre os recursos consumidos e as atividades.

De acordo com Duran e Radaelli (2000), deve-se definir o foco que o sistema de custeio $\mathrm{ABC}$ terá, ou seja, qual será a principal melhoria que o método trará para a empresa. Assim, é possível separar e gerenciar os processos das atividades, tornando o sistema de custos orçados e custos realizados mais organizado.

Na definição de Corrêa (2002), muitas empresas prestadoras de serviço encontram certa complexidade ao avaliarem seus resultados, pois não têm informações de quanto se está gastando em cada área operacional. Por conta disso, é implantado o método ABC como solução.

\section{Mensuração da lucratividade do cliente}

Os conceitos a respeito da avaliação do valor da lucratividade do cliente são encontrados predominantemente na literatura de marketing e em menor número nas esferas da contabilidade, do segmento hoteleiro e de bancos (WEIR, 2008).

Em geral, na literatura contábil, a avaliação e as métricas da lucratividade do cliente são contextualizadas holisticamente como customer accounting, a contabilidade focada no cliente e no seu envolvimento com os artefatos da contabilidade gerencial (GUILDING; MCMANUS, 2002; LIND; STRÖMSTEN, 2006; MANTOVANI; PEREIRA, 2017).

\section{PROCEDIMENTOS METODOLÓGICOS}

O trabalho caracteriza-se pela proposta de solução de um problema prático, para o qual será empregada uma metodologia para mensuração da lucratividade dos clientes da empresa Contábil. Dessa forma, a escolha pelo método intervencionista reside no fato de demonstrar como operacionalizar o processo de cálculo da rentabilidade do cliente.

A pesquisa é baseada em uma abordagem qualitativa intervencionista. Godoy (1995) afirma que esse tipo de pesquisa é valorizado por integrar o pesquisador e o seu objeto de estudo, mas considera importante também todo o processo que levou à obtenção dessas informações. A realização da pesquisa qualitativa envolve processos como analisar o segmento a ser estudado e a coleta de dados necessários, tendo como finalidade compreender o fe- 
nômeno que está sendo avaliado, pois, assim, será possível compreendê-lo no contexto de que faz parte.

A pesquisa intervencionista tem como objetivo fornecer elementos de sugestão para a organização estudada, conseguindo resultados úteis para toda a comunidade profissional, o que pode desencadear mudanças relevantes para a organização com novos conhecimentos que irão beneficiar a empresa (OYADOMARI et al., 2014).

Cassandre e Querol (2014) explicam que a intervenção tem como principal significado a ação de intervir, mediar e interceder, e pode ser aplicada em diversos contextos profissionais. No ramo contábil, a intervenção profissional também pode ser chamada de consultoria e tem como intuito melhorar uma determinada atividade.

Para Hatchuel (2000), pesquisas intervencionistas são como um modelo exigente de produção de conhecimento não só em teoria, mas também e principalmente na prática. Trata-se de um estudo em que o pesquisador precisa fazer um trabalho árduo e em longo prazo para o desenvolvimento de sua pesquisa.

\section{Ełapas do processo de intervenção}

O estudo apresenta uma intervenção no mecanismo de custeio da empresa Contábil. Para atingir o objetivo determinado, o processo foi dividido em quatro etapas. $1^{\mathrm{a}}$ - Entrevistas

A primeira etapa foi constituída de uma entrevista realizada com os sócios para identificar as principais atividades que a empresa exerce em seu dia a dia.

$3^{a}-$ Definir os direcionadores de recursos

A terceira etapa contemplou a discussão e a aplicação dos direcionadores do segundo estágio.

Nesse estágio, aloca-se o valor que cada cliente consumiu em determinada atividade.

\section{$2^{a}$ - Implantação do método ABC}

Segregamos os custos em grupos para sintetizar e simplificar o tratamento dos custos. A partir dessa separação, ocorre a alocação dos custos para as atividades definidas, com base nos direcionadores de custo (primeiro estágio) de cada atividade, as quais foram analisadas e discutidas com os sócios.

\section{$4^{a}$ - Cálculo da lucratividade}

O cálculo da rentabilidade foi a quarta e última etapa realizada. Nessa etapa, foram consideradas todas as receitas e despesas associadas a cada um dos clientes.

QUADRO 3 - Etapas da intervenção

Fonte: Elaborado pelos autores. 


\section{APRESENTAÇÃO E DISCUSSÃO DOS RESULTADOS}

\section{Implementação do método $A B C$}

Para alcançar o objetivo de mensurar a rentabilidade dos clientes, adotamos a recomendação de Torres, Silva e Matsumoto (2006), Martins (2003) e Padoveze (2015) que entendem que o $\mathrm{ABC}$ representa $\mathrm{o}$ método de custeio mais apropriado para esse fim. A empresa Contábil não utiliza nenhum mecanismo de controle de custos.

Nesse sentido, foi preciso implementar o método ABC na empresa. Para tanto, foram realizadas as seguintes etapas recomendadas por Martins (2003): 1. identificar as atividades relevantes; 2 . identificar e selecionar os direcionadores de recursos; 3. atribuir os custos dos recursos às atividades; 4. identificar e selecionar os direcionadores de atividades; e 5. atribuir os custos das atividades aos objetos de custeio.

Inicialmente foi realizada uma entrevista com os sócios da Contábil para definir quais são as atividades relevantes dentro da empresa. Martins (2003) considera relevantes as atividades que utilizam esforço humano, tempo de trabalho, número alto de demanda e conhecimentos tecnológicos e financeiros na produção de bens e serviços.

Como resultado, identificaram-se as seguintes atividades:

- Elaborar folha de pagamento.

- Elaborar demonstrações financeiras.

- Entregar obrigações acessórias.

- Elaborar registros contábeis.

- Participar de reunióes.

- Elaborar propostas.

- Fazer a gestão financeira.

Iniciou-se então a segunda fase do trabalho: implementação do método $\mathrm{ABC}$ nos gastos gerais da Contábil. Para isso, analisaram-se os custos e as despesas totais da empresa em um período de 12 meses, que se inicia em agosto de 2016 e termina em julho de 2017. De acordo com Martins (2003), a implantação do método ABC deve ser dividida em cinco etapas:

- Agrupar as contas de custos de acordo com sua natureza.

- Definir os direcionadores de custos para alocação direta na atividade.

- Atribuir os custos para as atividades.

- Definir os direcionadores de custos para alocação direta no cliente.

- Atribuir os custos das atividades para os clientes. 
A partir da Figura 2, é explicada a verticalização do processo de implementação do método $\mathrm{ABC}$.

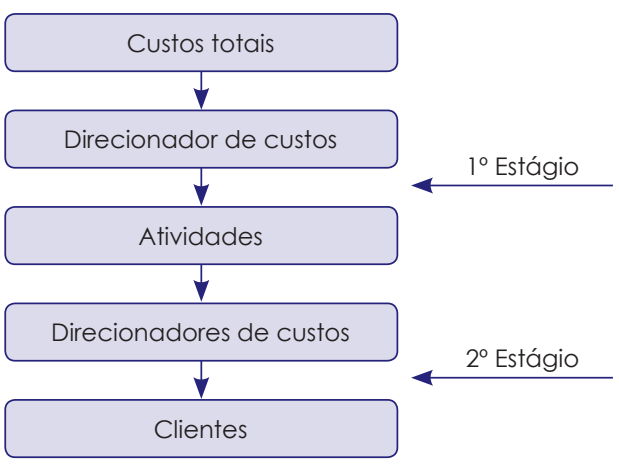

FigurA 2 - Etapas ABC

Fonte: Padoveze (2015).
Segundo Martins (2003, p. 65),

o custo de uma atividade compreende todos os sacrifícios de recursos necessários para desempenhá-la. Deve-se incluir salários com os respectivos encargos sociais, materiais, depreciação, energia, uso de instalações etc.

Dessa maneira, agrupamos vários itens de custo em uma única rubrica, refletindo seu gasto total (Quadro 4).

\begin{tabular}{ll}
\hline Custos fiscais & Documento de Arrecadação do Simples Nacional (DAS) \\
\hline Custos de remuneração & Salários, pró-labore, encargos sociais e benefícios \\
\hline Custos de comunicação & Telefone, internet e rede interna \\
\hline Custos de instalações & Aluguel, seguros, IPTU, condomínio, energia, água e manutenções \\
\hline Custos de viagens e deslocamentos & Combustíveis, pedágios e estacionamentos \\
\hline Custos administrativos & Material de escritório, higiene, cozinha e Conselho Regional \\
\hline de Contabilidade - CRC
\end{tabular}

QUADRO 4 - Grupos de custos

Fonte: Elaborado pelos autores.

Para Torres, Silva e Matsumoto (2006, p. 6), como as empresas prestadoras de serviço têm em sua estrutura de custos maior participação de custos indiretos, é recomendável a utilização do sistema $\mathrm{ABC}$, pois, conforme visto, ele permite a alocação 
dos custos aos produtos facilitando, de maneira mais apropriada, o gerenciamento.

TABELA 1 - Totais de custos

\begin{tabular}{lc}
\hline Custos & R\$ \\
\hline Custos fiscais & $20.604,91$ \\
\hline Custos de remuneração & $95.029,91$ \\
\hline Custos de comunicação & $9.291,91$ \\
\hline Custos de instalações & $72.635,85$ \\
\hline Custos de viagens e deslocamentos & $1.033,00$ \\
\hline Custos administrativos & $10.609,67$ \\
\hline Custos com terceiros & $13.113,73$ \\
\hline Custos financeiros & $2.391,43$ \\
\hline TOTAL & $\mathbf{2 2 3 . 9 4 4 , 4 1}$ \\
\hline
\end{tabular}

Fonte: Elaborada pelos autores.

Os gastos administrativos e os gastos financeiros foram caracterizados pelos sócios da Contábil como despesa, pois não estariam em ligação direta com a atividade-fim da empresa. Dessa maneira, foram alocados diretamente na atividade "fazer a gestão financeira" que compõe a maior atividade dos sócios no dia a dia.

Segundo Leone, Pedrosa Junior e Paulo (2014, p. 67):

Com a identificação dos custos aos departamentos, obtêm-se informações sobre o desempenho dos departamentos das empresas e, principalmente, diminui-se a subjetividade na apropriação dos custos indiretos aos portadores finais dos custos, devido à alocação dos custos identificáveis aos departamentos e, posteriormente, dos departamentos ao portador final, ambos os estágios com base em parâmetros mais coerentes.

\section{Atribuição de custos às atividades}

Para usarmos esse método de alocação, identificamos os direcionadores de custos em conjunto com um sócio da Contábil. Foi utilizado o critério quantitativo: a quantidade de recurso ou tempo que as atividades consomem para seu resultado final. De acordo com Morgan et al. (2014), entre os direcionadores, o tempo de trabalho é o principal gerador de custo especialmente na prestação de serviço.

No Quadro 5, estão elencados os direcionadores definidos para apropriar os custos consumidos pelas atividades.

Segundo Stefano et al. (2015, p. 19), "para efetuar o cálculo dos custos das atividades, examinaram-se cada tipo de recurso e atividades executadas, identificando quanto a organização gasta em cada atividade." 


\begin{tabular}{|c|c|}
\hline Custos/despesas & $\begin{array}{l}\text { Direcionadores } \\
\text { de custos }\end{array}$ \\
\hline Custos fiscais & Horas trabalhadas \\
\hline Custos de remuneração & Horas trabalhadas \\
\hline Custos de comunicação & $\begin{array}{c}\text { Número de lançamentos } \\
\text { contábeis realizados }\end{array}$ \\
\hline Custos de instalações & $\mathrm{M}^{2}$ \\
\hline $\begin{array}{c}\text { Custos de viagens e } \\
\text { deslocamentos }\end{array}$ & $\begin{array}{l}\text { Número de trabalhos } \\
\text { externos }\end{array}$ \\
\hline $\begin{array}{l}\text { Custos/despesas } \\
\text { administrativas }\end{array}$ & $\begin{array}{c}\text { Número de lançamentos } \\
\text { contábeis realizados }\end{array}$ \\
\hline Custos com terceiros & Horas trabalhadas \\
\hline $\begin{array}{l}\text { Custos/despesas } \\
\text { financeiras }\end{array}$ & $\begin{array}{c}\text { Número de lançamentos } \\
\text { contábeis realizados }\end{array}$ \\
\hline
\end{tabular}

QUADRO 5 - Direcionadores de custos Fonte: Elaborado pelos autores.

Identificados os grupos e totais, prosseguimos para a atribuição dos custos a essas atividades. Nesse processo, utilizamos o método de alocação direta.

Conforme Martins (2003), trata-se de um método de alocar o custo na atividade diretamente, pois existe identificação clara, direta e objetiva de relação.

De acordo com Leone, Pedrosa Junior e Paulo (2014), a alocação direta dos custos necessários para obtenção de serviços não depende do seu comportamento, fixo ou variável, ou seja, são tratados como custo do serviço e, consequentemente, repassados aos serviços, e, dessa forma, são alo- cados às atividades da empresa via os direcionadores de recursos identificados no Quadro 6.

TABELA 2 - Atribuição de custo para atividade

\begin{tabular}{lc}
\hline Atividades & R\$ \\
\hline Elaborar folha de pagamento. & $17.499,93$ \\
\hline Elaborar demonstrações financeiras. & $26.596,12$ \\
\hline Entregar obrigações acessórias. & $19.797,78$ \\
\hline Elaborar registros contábeis. & $26.596,12$ \\
\hline Participar de reuniões. & $43.260,63$ \\
\hline Elaborar proposta. & $9.035,71$ \\
\hline Fazer a gestão financeira. & $81.158,12$ \\
\hline Total & $\mathbf{2 2 3 . 9 4 4 , 4 1}$ \\
\hline
\end{tabular}

Fonte: Elaborada pelos autores.

Conforme Stefano et al. (2015), para efetuar o cálculo dos custos das atividades principais relacionadas ao trabalho, examinaram-se cada tipo de recurso e as atividades executadas, identificando os direcionadores e o quanto a empresa utilizou desse recurso no período estudado.

A seguir, demonstra-se o custo para servir que a Contábil possui, de acordo com suas atividades principais. O cálculo do custo unitário do direcionador é feito dividindo-se o custo total da atividade pelo volume de direcionador correspondente. 

LEONARDO FIORELLI CARMASSI

\begin{tabular}{ll}
\hline Atividades & Direcionadores \\
\hline Elaborar folha de pagamento. & Quantidade de holerites. \\
\hline Elaborar demonstrações financeiras. & Quantidade de emissões de demonstrações financeiras. \\
\hline Entregar obrigações acessórias. & Número de entregas. \\
\hline Elaborar registros contábeis. & Quantidade de registros contábeis. \\
\hline Participar de reuniões. & Número de reuniões. \\
\hline Elaborar proposta. & Número de propostas realizadas. \\
\hline Fazer a gestão financeira. & Número de registros financeiros. \\
\hline
\end{tabular}

QUADRO 6 - Atribuição de custo para os clientes

Fonte: Elaborado pelos autores.

\begin{tabular}{ll}
\hline Direcionadores & Totais dos clientes (12 meses) \\
\hline Quantidade de holerites processados. & 286 holerites \\
\hline Quantidade de emissões de demonstrações financeiras. & 394 emissões \\
\hline Número de obrigações acessórias entregues. & 699 entregas de obrigações \\
\hline Quantidade de registros contábeis. & 21.233 lançamentos \\
\hline Número de reuniões. & 57 reuniões \\
\hline Número de propostas realizadas. & 17 propostas \\
\hline Quantidade de registros financeiros. & 529 registros financeiros \\
\hline
\end{tabular}

QUADRO 7 - Direcionadores totais do período

Fonte: Elaborado pelos autores.

TABELA 3 - Cálculo do custo unitário

\begin{tabular}{lccc}
\hline Direcionadores & Total (12 meses) & Custo p/ atividade (R\$) & Custo un/ (R\$) \\
\hline Quantidade de holerites. & 286 holerites & $17.499,93$ & 61,18 \\
\hline Quantidade de demonstrações financeiras. & 394 emissões & $26.596,12$ & 67,50 \\
\hline Número de entregas. & 699 entregas & $19.797,78$ & 28,32 \\
\hline Quantidade de registros. & 21.233 registros & $26.596,12$ & 1,25 \\
\hline Número de reuniões. & 57 reuniões & $43.260,63$ & 758,96 \\
\hline Número de propostas. & 17 propostas & $9.035,71$ & 531,51 \\
\hline Número de inputs. & 529 inputs & $81.158,12$ & 153,42 \\
\hline
\end{tabular}

Fonte: Elaborada pelos autores. 
De acordo com Mauss e Costi (2004), no segundo estágio, são definidos os direcionadores de custos para as atividades. Por meio dos direcionadores de custos, torna-se racional o processo de alocar o consumo das atividades pelos objetos de custeio.

Para Mauss e Costi (2004, p. 5), essa é a grande contribuição do $\mathrm{ABC}$ para a tomada de decisões, tendo em vista a possibilidade de controle que o método oferece no nível de atividades desenvolvidas pela organização.

Conhecido o custo unitário do direcionador da atividade, ou seja, o direcionador do segundo estágio, pode-se atribuir o custo ao objeto de custeio, que nesse caso é o cliente da Contábil. O valor do custo atribuído a cada cliente corresponde ao volume de direcionadores de atividades utilizados ou consumidos por estes durante o período, multiplicado pelo seu valor unitário calculado na Tabela 3.

Dessa maneira, pode-se apurar o custo atribuído para cada cliente da empresa Contábil no período selecionado, conforme demonstra a Tabela 4.
TABELA 4 - Atribuição de custos aos clientes

\begin{tabular}{|c|c|}
\hline Clientes & $\begin{array}{l}\text { Custo atribuído } \\
\text { aos clientes (R\$) }\end{array}$ \\
\hline Cliente A & $1.951,49$ \\
\hline Cliente B & $1.668,96$ \\
\hline Cliente C & $3.814,81$ \\
\hline Cliente D & $2.391,32$ \\
\hline Cliente E & $2.934,98$ \\
\hline Cliente F & $9.037,78$ \\
\hline Cliente G & $3.939,72$ \\
\hline Cliente H & $3.885,20$ \\
\hline Cliente I & $5.907,77$ \\
\hline Cliente J & $10.080,19$ \\
\hline Cliente K & $6.086,15$ \\
\hline Cliente L & $2.786,66$ \\
\hline Cliente M & $2.758,94$ \\
\hline Cliente N & $1.633,62$ \\
\hline Cliente O & $14.500,66$ \\
\hline Cliente P & $3.644,14$ \\
\hline Cliente Q & $13.356,83$ \\
\hline Cliente R & $7.104,24$ \\
\hline Cliente S & $14.800,23$ \\
\hline Cliente T & $5.204,16$ \\
\hline Cliente U & $43.527,37$ \\
\hline Cliente V & $4.846,57$ \\
\hline Cliente W & 839,70 \\
\hline Cliente X & $8.810,13$ \\
\hline Cliente Y & $9.021,58$ \\
\hline Cliente Z & $5.735,43$ \\
\hline Cliente AA & $33.810,91$ \\
\hline TOTAL & $223.944,41$ \\
\hline
\end{tabular}

Fonte: Elaborada pelos autores. 


\section{Mensuração da lucratividade dos clientes}

De acordo com Garrison (2007), a receita de vendas ou de serviços constitui uma base simples e de fácil utilização para mensurarmos a rentabilidade de algum produto ou cliente, sendo um mecanismo de controle para absorção de custos.

A partir do cálculo das receitas de todos os clientes dentro do período, obtemos a rentabilidade de cada cliente da Contábil. Assaf Neto (2009) afirma que a rentabilidade pode ser uma avaliação econômica do desempenho da empresa dentro de um determinado período, conforme mostra a Tabela 5.

Segundo o Conselho Federal de Contabilidade (2016), a receita obtida para o ano corrente ou período estudado pode servir como base para predizer receitas futuras e ser comparada com predições de receita para o ano corrente que foram feitas nos anos anteriores. $\mathrm{O}$ resultado dessas comparações pode auxiliar os usuários e gestores a corrigir e melhorar os processos que foram utilizados para fazer tais predições.
TABELA 5 - Receita do período de 12 meses

\begin{tabular}{|c|c|}
\hline Clientes & $\begin{array}{l}\text { Receitas da Contábil } \\
\text { (12 meses) (R\$) }\end{array}$ \\
\hline Cliente A & $1.320,00$ \\
\hline Cliente B & 351,00 \\
\hline Cliente C & $5.472,00$ \\
\hline Cliente D & $1.600,00$ \\
\hline Cliente E & $1.606,00$ \\
\hline Cliente F & $39.166,65$ \\
\hline Cliente G & $1.660,00$ \\
\hline Cliente H & $1.872,00$ \\
\hline Cliente I & $2.800,00$ \\
\hline Cliente J & $11.782,00$ \\
\hline Cliente K & $3.972,00$ \\
\hline Cliente L & $1.400,00$ \\
\hline Cliente M & $1.000,00$ \\
\hline Cliente N & 900,00 \\
\hline Cliente O & $12.000,00$ \\
\hline Cliente P & $5.448,00$ \\
\hline Cliente Q & $11.782,00$ \\
\hline Cliente R & $21.000,00$ \\
\hline Cliente S & $22.500,00$ \\
\hline Cliente T & $1.872,00$ \\
\hline Cliente U & $70.340,00$ \\
\hline Cliente V & $3.220,00$ \\
\hline Cliente W & $20.000,00$ \\
\hline Cliente X & $5.072,00$ \\
\hline Cliente Y & $16.583,33$ \\
\hline Cliente Z & $3.572,00$ \\
\hline Cliente AA & 0 \\
\hline TOTAL & $268.290,98$ \\
\hline
\end{tabular}

Fonte: Elaborada pelos autores. 
De acordo com Hastenteufel e Larentis (2015), a análise da rentabilidade de clientes é obtida com a apuração dos custos para atender determinado cliente comparada à receita bruta de serviços do período. Por meio dessa análise, é obtida a lucratividade individual de cada cliente.

A partir da Tabela 6, pode-se observar que no período estudado, dentre os 27 clientes, apenas nove são rentáveis e lucrativos para a Contábil. Contudo, a situação da empresa ainda é estável, pois seus maiores clientes são rentáveis. Dessa maneira, a empresa conseguiu obter uma margem de lucro razoável para o período estudado.

O resultado apresentado apura os impactos operacionais e financeiros que cada cliente causa na empresa. Esse ferramental auxilia os gestores na mensuração da lucratividade de cada cliente. Ademais, com a informação de quais atividades consomem mais recursos da empresa, há espaço para análises futuras.

A análise dos dados identifica os custos e as atividades que mais impactaram os clientes da Contábil no período, e os custos de instalação e remuneração foram os mais elevados, impactando diretamente duas atividades que recebem a utilização de todos os clientes e fazem parte do grupo de atividades mais executadas: "participar de reuniões" e "fazer a gestão financeira".

Dessa forma, igualam-se as atividades "elaborar registros contábeis" e "elaborar demonstrações financeiras", que são atividades essenciais da empresa e foram grandes receptoras de custos.

Os dados mostram que as atividades "entregar obrigações acessórias", "elaborar propostas" e "elaborar folha de pagamento" foram as menos impactadas pela alocação de custos, pois são atividades que podem variar de acordo com a necessidade de cada cliente.

A análise dos clientes mais lucrativos e rentáveis apresentados mostra que a empresa atualmente possui um grande potencial com clientes considerados "grandes", pois, apesar de gerar mais trabalho e mais custo ao longo do tempo para a empresa, gera constantemente uma receita mensal apropriada e suficiente para a Contábil cobrir os seus resultados negativos com outras empresas consideradas menores e não rentáveis.

Os clientes não rentáveis para a Contábil representam $67 \%$ da carteira da empresa atualmente. De acordo com a análise dos dados, esses clientes consomem uma grande quantidade de atividades que não estavam compreendidas na proposta inicial de prestação de serviços. 
TABELA 6 - Rentabilidade sobre os clientes

\begin{tabular}{|c|c|c|c|}
\hline Clientes & Receita (12 meses) & Custo alocado (R\$) & Lucro/prejuízo (R\$) \\
\hline Cliente A & $1.320,00$ & $(1.951,49)$ & $-631,49$ \\
\hline Cliente B & 351,00 & $(1.668,96)$ & $-1.317,96$ \\
\hline Cliente C & $5.472,00$ & $(3.814,81)$ & $1.657,19$ \\
\hline Cliente D & $1.600,00$ & $(2.391,32)$ & $-791,32$ \\
\hline Cliente E & $1.606,00$ & $(2.934,98)$ & $-1.328,98$ \\
\hline Cliente F & $39.166,65$ & $(9.037,78)$ & $30.128,87$ \\
\hline Cliente G & $1.660,00$ & $(3.939,72)$ & $-2.279,72$ \\
\hline Cliente H & $1.872,00$ & $(3.885,20)$ & $-2.013,20$ \\
\hline Cliente I & $2.800,00$ & $(5.907,77)$ & $-3.107,77$ \\
\hline Cliente J & $11.782,00$ & $(10.080,19)$ & $1.701,81$ \\
\hline Cliente K & $3.972,00$ & $(6.086,15)$ & $-2.114,15$ \\
\hline Cliente L & $1.400,00$ & $(2.786,66)$ & $-1.386,66$ \\
\hline Cliente M & $1.000,00$ & $(2.758,94)$ & $-1.758,94$ \\
\hline Cliente N & 900,00 & $(1.633,62)$ & $-733,62$ \\
\hline Cliente O & $12.000,00$ & $(14.500,66)$ & $-2.500,66$ \\
\hline Cliente P & $5.448,00$ & $(3.644,14)$ & $1.803,86$ \\
\hline Cliente Q & $11.782,00$ & $(13.356,83)$ & $-1.574,83$ \\
\hline Cliente R & $21.000,00$ & $(7.104,24)$ & $13.895,76$ \\
\hline Cliente S & $22.500,00$ & $(14.800,23)$ & $7.699,77$ \\
\hline Cliente T & $1.872,00$ & $(5.204,16)$ & $-3.332,16$ \\
\hline Cliente U & $70.340,00$ & $(43.527,37)$ & $26.812,63$ \\
\hline Cliente V & $3.220,00$ & $(4.846,57)$ & $-1.626,57$ \\
\hline Cliente W & $20.000,00$ & $(839,70)$ & $19.160,30$ \\
\hline Cliente X & $5.072,00$ & $(8.810,13)$ & $-3.738,13$ \\
\hline Cliente Y & $16.583,33$ & $(9.021,58)$ & $7.561,75$ \\
\hline Cliente Z & $3.572,00$ & $(5.735,43)$ & $-2.163,43$ \\
\hline Cliente AA & 0 & $(33.810,91)$ & $-33.810,91$ \\
\hline TOTAL & $268.290,98$ & $(223.944,41)$ & $44.346,57$ \\
\hline
\end{tabular}

Fonte: Elaborada pelos autores. 
Contudo, é preciso considerar os altos custos e as despesas em que a empresa incorreu durante o período, em destaque os custos de instalação e de remuneração, que contribuíram fortemente para o resultado negativo na maioria dos clientes.

\section{CONSIDERAÇÕES FINAIS}

O objetivo do trabalho foi realizar uma pesquisa intervencionista visando implementar um mecanismo de controle de custos por meio do método $\mathrm{ABC}$ em uma empresa prestadora de serviços contábeis.

O grau de intervenção e o sucesso deste trabalho classificam-se como altamente positivos, pois os pesquisadores desenvolveram o modelo com dados reais e confiáveis da empresa, que autorizou o estudo e permitiu o acesso aos dados do negócio.

Antes de iniciar a intervenção, a empresa não praticava nenhum mecanismo de controle de custos e rentabilidade. $\mathrm{O}$ desenvolvimento do estudo transcorreu de boa forma, em virtude da estreita relação entre os administradores e pesquisadores.

A pesquisa e as apresentações do resultado geraram interesse para os sócios da empresa, que não tinham o conhecimento do custo para servir seus clientes. Os resul- tados da pesquisa demonstraram que mais de $50 \%$ dos clientes não eram rentáveis.

Por fim, pode-se concluir que os efeitos dessa intervenção foram relevantes para os sócios da Contábil, pois eles conseguiram, a partir da metodologia implementada, analisar com mais clareza os seus procedimentos e processos, e, a partir do uso contínuo, tomar decisões mais assertivas.

\section{MEASUREMENT OF CUSTOMER PROFITABILITY IN AN ACCOUNTING FIRM}

\section{ABSTRACT}

The verification of the measurement of the clients' profitability is an essential tool for the control and economic situation of the company, but many do not use this managerial method due to lack of resources, lack of knowledge or even considering it unnecessary to use. In this way, the present study aimed to implement a cost control mechanism in the company that can measure the profitability that each client represents for the company, presenting managers with a more transparent result on their profitability, and the importance of managerial control. One company, which did not use the mentioned method, was selected and, from that, sought to demonstrate the benefits that this 
mechanism can bring. The intervention showed the managers a clear vision of which customers are profitable and not profitable for the company, in addition to indicating possible improvement processes.

\section{KEYWORDS}

Customer profitability. Activity based costing. Accounting firm.

\section{REFERÊNCIAS}

ASSAF NETO, A. Finanças corporativas e valor. 4. ed. São Paulo: Atlas, 2009.

BRIMSON, J. A. Contabilidade por atividades: uma abordagem de custeio baseado em atividades. São Paulo: Atlas, 1996.

CASSANDRE, M. P.; QUEROL, M. A. P. Metodologias intervencionistas: contribuição teórico-metodológica vigotskyanas para aprendizagem organizacional. Revista Pensamento Contemporâneo em Administração, v. 8, n. 1, p. 17-34, 2014.

CONSELHO FEDERAL DE CONTABILIDADE. Resolução CFC n. 1.374, de 8 de dezembro de 2011. Disponível em: https:// cfc.org.br/. Acesso em: 26 out. 2017.

CORRÊA, R. C. Custos em empresas prestadoras de serviços de informática: aplicação do ABC. Florianópolis: UFSC, 2002.
DURAN, O.; RADAELLI, L. Metodologia ABC: implantação numa microempresa. Gestão \& Produção, v. 7, n. 2, p. 118-135, 2000 .

FERREIRA, J. A. Custos industriais: uma ênfase gerencial. São Paulo: STS, 2007.

GARRISON, R. H. Contabilidade gerencial. 11. ed. São Paulo: LTC, 2007.

GODOY, A. S. Pesquisa qualitativa: tipos fundamentais. Revista de Administração de Empresas, v. 35, n. 3, p. 20-29, 1995.

GUERREIRO, R.; BIO, S. R.; MERSCHMANN, E. V. V. Cost-to-serve measurement and customer profitability analysis. International Journal of Logistic Management, v. 19, n. 3, p. 389-407, 2008a.

GUERREIRO, R.; MERSCHMANN, E. V. V.; BIO, S. R. Mensuração do custo para servir e análise de rentabilidade de cliente: uma aplicação em indústria de alimentos no Brasil. Revista de Administração - eletrônica, São Paulo, v. 1, n. 2, 2008 b.

GUERREIRO, R.; PEREIRA, C. A.; REZENDE, A. J. Em busca do entendimento da formação dos hábitos e das rotinas da contabilidade gerencial: um estudo de caso. Revista de Administração Mackenzie, v. 7, n. 2, 2008c. 
GUILDING, C.; MCMANUS, L. The incidence, perceived merit and antecedents of customer accounting: an exploratory note. Accounting, Organizations and Society, v. 27, p. 45-59, 2002.

GUPTA, S.; LEHMANN, D. R. Customer lifetime value and firm valuation. Journal of Relationship Marketing, v. 5, n. 2-3, p. $87-110,2006$.

HASTENTEUFEL, C.; LARENTIS, F. Análise da rentabilidade de clientes através da margem de contribuição: um estudo em uma empresa de médio porte do setor moveleiro localizada na Serra Gaúcha. Revista Produção e Desenvolvimento, v. 1, n. 1, p. 60-76, 2015.

HATCHUEL, A. Intervention research and the production of knowledge. In: CERF, M. et al. Cow up a tree. Knowing and learning for change in agriculture. Case studies from Industrialised Countries. Paris: Inra, 2000. p. 55-68.

IUDÍCIBUS, S. de. Contabilidade gerencial. 6. ed. São Paulo: Atlas, 1998.

KAPLAN, R. S.; COOPER, R. Custo e desempenho: administre seus custos para ser mais competitivo. São Paulo: Futura, 1998.

KAPLAN, R. S.; NARAYANAN, V. G. Customer profitability measurement and management. Harvard Business School, n. 5, 2001.

KAPLAN, R. S.; NORTON, D. Mapas estratégicos. Barcelona: Gestión, 2000.

LEONE, G. S. G. Curso de contabilidade de custos. São Paulo: Atlas, 1997.

LEONE, G. S. G.; PEDROSA JUNIOR, C.; PAULO, E. Taxinomia dos sistemas de custeio e alocação de custos. Revista Eletrônica do Mestrado Profissional em Administração da Universidade Potiguar, v. 6, n. 1, p. 61-70, 2014.

LIND, J.; STRÖMSTEN, T. When do firms use different types of customer accounting. Journal of Business Research, v. 59, n. 12, p. 1257-1266, 2006.

MANTOVANI, F. R. Desenho e uso de sistemas de controle gerencial focados nos clientes: um estudo em empresas brasileiras sob a perspectiva da teoria da contingência. 2012. Tese (Doutorado em Controladoria e Contabilidade) - Universidade de São Paulo, São Paulo, 2012.

MANTOVANI, F. R.; PEREIRA, C. A. Management control systems focused on the customer: evidence from Brazil. Journal of Marketing Management, v. 5, n. 1, p. 45-55, 2017.

MARTINS, E. Contabilidade de custos. 9. ed. São Paulo: Atlas, 2003. 
MAUSS, C. V.; COSTI, R. M. O método de custeio $A B C$ como instrumento de gestão. São Paulo: Atlas, 2004.

MORGAN, B. F. et al. Tempo como direcionador do custo: mensuração por observação direta e entrevista. In: CONGRESSO BRASILEIRO DE CUSTOS-ABC, Natal, 2014. Anais do Congresso Brasileiro de Custos. Disponível em: anaiscbc.emnuvens.com.br. Acesso em: 24 nov. 2017.

MOURA, H. da S. O custeio por absorção e o custeio variável: qual seria o melhor método a ser adotado pela empresa. Santana: UEFS, 2005.

NAKAGAWA, M. ABC: custeio baseado em atividades. São Paulo: Atlas, 1994.

OYADOMARI, J. C. T. et al. Pesquisa intervencionista: um ensaio sobre as oportunidades e riscos para pesquisa brasileira em contabilidade gerencial. Advances in Scientific and Applied Accounting, v. 7, n. 2, p. 244-265, 2014.

PADOVEZE, C. L. Contabilidade de custos: teoria, prática, integração com sistemas de informação (ERP). São Paulo: Cengage Learning, 2015.

RIBEIRO, O. M. Contabilidade de custos fácil. São Paulo: Saraiva, 1997.

ROBLES JR., A.; ROBLES, L. T.; FARIA, A. C. de. Custos para servir: uma proposta de aplicação para uma empresa de tintas. Revista Universo Contábil, v. 1, n. 1, p. 71-85, 2005.

ROSS, S. A.;JORDAN, B. D.; WESTERFIELD, R. W. Administração financeira. 8. ed. São Paulo: McGraw Hill, 2008.

SERVIÇO BRASILEIRO DE APOIO ÀS MICRO E PEQUENAS EMPRESAS. 6 dicas para ter uma boa contabilidade. 2012. Disponível em: http://www.boletimdoempreendedor.com.br/boletim.aspx?codBoletim=678_6_dicas_para_te. Acesso em: 21 maio 2017.

SERVIÇO BRASILEIRO DE APOIO ÀS MICRO E PEQUENAS EMPRESAS. Cálculo da lucratividade do seu negócio. 2016. Disponível em: https://www.sebrae.com.br/sites/PortalSebrae/artigos/ calculo-da-lucratividade-do-seu-negocio, 21 a 1 ebb38b5f2410 Vgn VCM 100000b272010aRCRD. Acesso em: 23 maio 2017.

STEFANO, N. M. et al. Uma proposta de gerenciamento de custos em pequenas organizações de serviço utilizando o activity based costing. ABCustos, v. 5, n. 2, p. 1-31, 2015.

THOMÉ, I. Empresas de serviços contábeis: estrutura e funcionamento. São Paulo: Atlas, 2001. 
TORRES, S. B.; SILVA, A. dos S.; MATSUMOTO, A. S. Análise para implantação do método de custeio baseado em atividade - ABC. In: CONGRESSO BRASILEIRO DE CUSTOS-ABC, 2006. Anais... Disponível em: https://anaiscbc.emnuvens.com.br/anais. Acesso em: 24 nov. 2017.

VANDERBECK, E. J.; NAGY, C. F. Contabilidade de custos. 11. ed. São Paulo: Pioneira, 2001.

WEIR, K. Examining the theoretical influences of customer valuation metrics. Journal of Marketing Management, v. 24, n. 7-8, p. 797-824, 2008. 